8. Malyoth, G. and Bauer, A., Observations on Bacterium bifidum. Z. Kinderhelikd., 1950, 68(4), 358.

9. Culpepper, T. et al., Bifidobacterium bifidum R0071 decreases stress associated diarrhoea-related symptoms and self-reported stress: a secondary analysis of a randomised trial. Benef. Microbes, 2016, 7(3), 327-336.

10. Saarela, M., Mogensen, G., Fonden, R., Mättö, J. and MattilaSandholm, T., Probiotic bacteria: safety, functional and technological properties. J. Biotechnol., 2000, 84(3), 197-215.

11. Siaterlis, A., Deepika, G. and Charalampopoulos, D., Effect of culture medium and cryoprotectants on the growth and survival of probiotic lactobacilli during freeze drying. Lett. Appl. Microbiol., 2009, 48, 295-301.

12. Veda, M. O., Nakamoto, S., Nakai, R. and Takagi, A., Establishment of a defined minimal medium and isolation of auxotrophic mutants for Bifidobacterium bifidum ES 5. J. Gen. Appl. Microbiol., 1983, 29(2), 103-114.

13. Gaden Jr, E. L., Fermentation process kinetics. Biotechnol. Bioeng., 2000, 67(6), 629-635.

14. Corre, C., Madec, M. N. and Boyaval, P., Production of concentrated Bifidobacterium bifidum. J. Chem. Technol. Biotechnol., 1992, 53(2), 189-194.

15. De Man, J. C., Rogosa, M. and Sharpe, M. E., A medium for the cultivation of lactobacilli. J. Appl. Bacteriol., 1960, 23, 130-135.

16. Vinderola, C. G. and Reinheimer, J. A., Culture media for the enumeration of Bifidobacterium bifidum and Lactobacillus acidophilus in the presence of yoghurt bacteria. Int. Dairy J., 1999, 9(8), 497-505.

17. Coghetto, C. C., Brinques, G. B., Siqueira, N. M., Pletsch, J., Soares, R. M. and Ayub, M. A., Electrospraying microencapsulation of Lactobacillus plantarum enhances cell viability under refrigeration storage and simulated gastric and intestinal fluids. $J$. Funct. Foods, 2016, 24, 316-326.

18. Meena, G. S., Gupta, S., Majumdar, G. C. and Banerjee, R., Growth characteristics modeling of Bifidobacterium bifidum using RSM and ANN. Braz. Arch. Biol. Technol., 2011, 54(6), 13571366.

19. Dinakar, P. and Mistry, V. V., Growth and viability of Bifidobacterium bifidum in cheddar cheese. J. Dairy Sci., 1994, 77(10), 2854-2864.

20. Hekmat, S., Survival of Lactobacillus acidophilus and Bifidobacterium bifidum in ice cream for use as a probiotic food. J. Dairy Sci., 1992, 6, 1415-1422.

21. Kulkarni, S., Haq, S. F., Samant, S. and Sukumaran, S., Adaptation of Lactobacillus acidophilus to thermal stress yields a thermotolerant variant which also exhibits improved survival at $\mathrm{pH} 2$. Probiot. Antimicrob. Proteins, 2018, 10(4), 717-727.

22. Hwang, C. F., Lin, C. K., Yan, S. Y., Chang, R. H. and Tsen, H. Y., Enhancement of biomass production and nutrition utilization by strain Lactobacillus acidophilus DGK derived from serial subculturing in an aerobic environment. Afr. J. Biotechnol., 2015, 14(3), 248-256.

23. Ram, C. and Chander, H., Optimization of culture conditions of probiotic bifidobacteria for maximal adhesion to hexadecane. World J. Microbiol. Biotechnol., 2003, 19(4), 407-410.

24. Mlobeli, N. T., Batch culture studies of Bifidobacterium bifidum: a thesis presented in partial fulfilment of the requirements for the degree of Master of Technology in Biotechnology and Bioprocess Engineering, Doctoral dissertation, Massey University, 1996.

25. Kwon, S. G., Son, J. W., Kim, H. J., Park, C. S., Lee, J. K., Ji, G. E. and Oh, D. K., High concentration cultivation of Bifidobacterium bifidum in a submerged membrane bioreactor. Biotechnol. Prog., 2006, 22(6), 1591-1597.

Received 25 January 2019; revised accepted 9 September 2019

doi: $10.18520 / \mathrm{cs} / \mathrm{v} 118 / \mathrm{i} 2 / 280-285$

\section{Pigment analysis of palm leaf manuscripts of India}

\author{
Deepakshi Sharma ${ }^{1, *}$, Manager Singh ${ }^{1}$, \\ Gabriela Krist ${ }^{2}$ and M. Velayudhan Nair ${ }^{3}$ \\ ${ }^{1}$ National Museum Institute, Department of Conservation, \\ Janpath, New Delhi 110 011, India \\ ${ }^{2}$ Institute of Conservation, University of Applied Arts Vienna, Austria \\ ${ }^{3}$ Department of Culture, Government of Kerala, Thiruvananthapuram \\ 695033 , India
}

The primary aim of this study is to scientifically examine major pigments and binders used in Indian palm leaf manuscripts. The colours in four painted palm leaf manuscripts (18th-19th century CE) were observed using a digital microscope and SEM-EDX. Analytical studies showed that the colours were prepared using traditional Indian techniques by mixing primary pigments like black, red, white, yellow, blue and green with locally available gum or adhesive. The prominent appearance of black or brown stains, discolouration and insect activity were the major causes for making the leaves brittle and unstable. The identification of pigments also provided rich source of information about the composition and development of painting traditions on palm leaf in India's southern and eastern parts. Laboratory studies also revealed the use of mineral as colourant for Indian palm leaf illustrations.

Keywords: Binders, palm leaf manuscripts, painting traditions, pigments.

THE earliest imprints of human activities in India have always been through oral tradition. As part of Hindu tradition, knowledge has been transmitted orally to the future generations. The emphasis of spoken language led to the negligence of writing tradition. India was always considered a land of tradition which has transmitted orally from one generation to another until the writing system came into existence. The concept of writing system in India started much later than its language. The first reference to writing in India was found in Pali Buddhists canon of the 5 th century BC (ref. 1). Consequently, writing became a means of transmitting and documenting knowledge that would otherwise be $\operatorname{lost}^{2}$. Hence the recorded knowledge in the form of manuscripts has played an essential role in the development, preservation and propagation of learning and literature in India, down the ages. Recording them in writing form on a large scale was the only solution to preserve and propagate them for future generations.

India is a hub of the oldest traditions in the form of manuscripts. Before the invention of paper, various mediums such as stone, clay tablet, metal, wood, birch bark

*For correspondence. (e-mail: sharmadeepakshi1@gmail.com) 
(canoe made with bark of birch tree), Sanchipat (sheet made from agar or aloe tree), palm leaf, cotton cloth and parchment were used for recording text and written communication. These mediums have proved to be efficient, portable and small, which led to their growth and development. In due course of time, various mediums have influenced and transformed the Indian scripts ${ }^{3}$. According to ancient Indian Tamil literature, there were three modes of graphic communication in ancient Tamil Nadu. In the Indian subcontinent and of Southeast Asia, palm leaves were a traditional support to inscribe decoration and script or paint illustrations and ink ${ }^{4}$. Before the introduction of paper, palm leaf was a popular medium for writing and painting in Southeast Asian countries such as Myanmar, Thailand, Malaysia, Indonesia and Sri Lanka ${ }^{5}$. Palm leaf is a generic term; hence, vernacular names are used in various regions which often imply a variety of leaves. In Sri Lanka the palm leaf is known as 'ola', in Thailand as 'Larn', in Myanmar as 'Lontar', and various parts of India as 'Tula', 'Sritala' or 'Karalika' . Large collections of manuscripts on palm leaves are found in museums, libraries and private collections. Development of conservation ideas and practices in this sphere has been rather limited. As a result, dependable literature on traditions of palm leaf and its conservation is rare and scarce.

Palm leaves are organic in nature. They are subjected to swelling or contracting due to their high reactivity to water. They break easily in dry environment, leading to ultimate crumbling. Being composed of cellulose and lignin, palm leaves get bleached/darkened easily under UV light. They are sensitive to mechanical impact resulting in scratches, folds, breaks and splits.

Palm leaf trees are of long feather fronds or fanshaped. The old leaf scars form a hard, regular pattern on the trunk. Palm trees are generally found on sandy soil in tropical countries ${ }^{6}$. They are well-known for longevity due to life span over which constituent cells can function metabolically ${ }^{7}$. In the evolution of the art of writing, script and language, palm leaf manuscript is an invaluable source, which codifies and preserves human expression. It is still surviving in the shops and bazaars, in some friendly native household, in a temple or with an astrologer. Many specimens of the original materials are available in various libraries in India, but they are brittle and under decay. In some parts of India, the palm leaf manuscript itself is the object of worship and the essence of the text is personified in the name of a God or Goddesses. Many temples still use palm leaf manuscripts for reference instead of religious books. Several families in rural communities keep a collection of palm leaf manuscripts near their household deities and offer prayers to them. People also preserve manuscripts in their homes carefully, because they consider these as inheritances from their ancestors. In some areas, the text available on the palm leaf manuscripts and religious books in various libraries are read and referred, rather than from the printed books. In social life, the art of palm leaf inscription is used even today for recording the horoscope of new-born babies ${ }^{8}$.

There are numerous varieties of palm leaves available all over the world. However, only two leaf species have originated in India, viz. Srital/palmyra (Borassus flabelliferlinn) and Talipot (Coryphaum braculiferalinn). Both are found in abundance in states like Odisha, Kerala, Tamil Nadu, Karnataka and Andhra Pradesh. Traditionally, palm leaf writing has been passed on from one generation to another through scholars and scribes ${ }^{9}$.

For processing and preparation of palm leaf manuscripts, various methods are used which differ from one region to another. For example, there might be diverse methods for preparation in South India, whereas Odisha and other Southeast Asian countries have adopted different techniques. The basic method of palm leaf preparation for writing is as follows ${ }^{10}$. After incision, the letters are generally not visible to read the text. Therefore, lamp black or coal powder mixed with oil in applied on the leaves, which makes the letters clear and readable. The excess mixture is wiped-off with a soft/muslin cloth. Sometimes, fresh green leaves of a tree are rubbed on the palm leaves so that the green juice of leaves gets deposited in the engravings to make them more visible ${ }^{2}$.

Writing on palm leaf differs from region to region. In general, two major techniques were used for writing on palm leaf ${ }^{5}$. In the first technique, a brush or red pen dipped in a pot of ink was used for writing. This was done in the usual manner as with pen on paper. The incisions were filled with black and sometimes red colour. The choice of colour was quite restricted to yellow, red, blue, green, white and black, and their mixtures ${ }^{5}$. Since palm leaf is less absorbent than paper, the ink remains on the surface.

In the second method, incision was made with a stylus. The stylus was held in the right hand at a fixed place on the leaf. The leaf was held in the left hand and moved backwards and forwards to make the incision. This method was most prevalent in South India. In the other method, writing was done by moving the stylus. In Odisha, the scribe is also known as lekhanakara, who uses a lekhani (iron stylus) to etch on the palm leaf surface. The stylus is usually plain, but can also be ornamental. While writing, the scribe generally leaves space for embellishment and illustrations. One often comes across blank spaces between the text in incomplete manuscripts. This confirms that the text was written first, leaving blank spaces for illustrations which were done later.

The palm leaf manuscripts have both text and illustrations, either incised or painted with a brush. At a few places, after the process of etching, the juice of bean leaves (simva) mixed with black soot (lamp black) or any desired colour was applied to make the etchings legible. The pigments/colours which have been used in decorating the leaves were basically red, green, black, blue, white 


\section{RESEARCH COMMUNICATIONS}

and yellow. It has been found that these pigments were extracted naturally from locally available materials ${ }^{9,11}$. For example, black has been extracted from lamp black, red from cinnabar, white from conch shell powder, yellow from turmeric powder, blue from indigo plant leaves and green from ground bean leaves ${ }^{7,12}$. Therefore, pigments were prepared in a traditional way and applied on the manuscripts. They were mixed with locally available gum or adhesive as binding medium before application.

In India, pigments used in palm leaf have still not been scientifically evaluated. Although many non-invasive techniques are now being applied for identification of pigments and the binding medium, the owners of palm leaf manuscripts are not ready to part with their materials. This has resulted in the lack of scientific analysis on the pigments or microstructure of the leaves to understand causes of their brittleness. In the present study, we identify pigments of palm leaves on material sourced from an unknown artist in Odisha.

According to the literature and continuing tradition in various parts of India, after writing the palm leaf manuscript, bundles are placed between two wooden planks and tied with a cotton thread/cord. The bundles are generally wrapped in a cotton cloth, preferably red because this colour prevents insect attack. Another reason for wrapping the bundles in a cotton cloth is to protect them from dust and dirt. Finally, the bundles are kept safe in a wooden or metal almirah/cupboard ${ }^{13}$.

Sampling strategy is the first step in the analysis of palm leaf manuscripts. Four painted palm leaf manuscripts from an unknown artist in Odisha were collected to identify the pigments used for writing (Figure 1). It was assumed through discussion with the owner that these folios belong probably to late 18 th or early 19 th century CE. Attention was given to locate and describe the painting techniques (stratigraphy of pigments). Appropriate representative visible various colour pigments (blue, green, yellow, red, black and white) were located on the manuscripts and labelled accordingly. To accurately determine elemental composition of all the pigments visible on the leaves, 24 measuring points were selected.

Pigments were also observed under the digital microscope (Dino-Lite Edge, 200×, 5 megapixels, AM7915M27 Series) to study their nature and composition.

The element composition of selected colours was measured using a scanning electron microscope with energy-dispersive analyser (SEM-EDX; SEM FEI QUANTA FEG 250, EDX Analyser EDAX, Apollo-X Detector, EDX Software Genesis V.6.1). Measurements were made under low vacuum without sputtering.

For further analysis, the pigments were powdered thoroughly and observed under polarized light microscope (PLM) (Nikon Eclipse ME 600 microscope fitted with digital camera Nikon Coolpix 990; $100 \mathrm{~W}$ halogen lamp). Pigments identification was carried out based on charac- terization of the morphological and optical properties under PLM.

Under polarized light microscope, the blue pigment showed a variety in colours ranging from deep to light crystals spread within a transparent matrix and rich in detachment part. The pigment aggregates varied in colour from medium blue to black with a characteristic band of indigo ${ }^{14}$.

Under the microscope, the green pigment area showed various shades and green particles were pale and sometimes faded showing detachment of pigment particles in some portions (Figure 2). Hence it was difficult to characterize the actual band of green pigment. On careful observation under the microscope, the yellow layer appeared to have different shades like bright yellow that also showed small and rounded grains of the pigment (Figure 3). Therefore, it was difficult to characterize the actual component of yellow pigment through microscopic studies.

The white paint layer was slightly thick and further analysis was necessary to confirm the actual elemental composition of the pigment. Red pigment indicated enhancing transition from dark red to light red. For actual elemental composition of red pigment, further analysis was required (Figure 3). Black paint was observed both in illustrations as well as text. It gave a glossy effect and showed large grains of pigment (Figure 2). In a few portions, cracks were visible under the microscope. Another important observation was cell structures on the leaf, although it was difficult to find the morphological structure through this analysis (Figure 4).

Using PLM, grains of white and blue pigments were observed in the powder preparation of colour for illustrations. Based on the elemental composition of the measured blue and white portions, and the morphological and optical properties of the pigments, it was concluded that blue paint contains indigo $\left(\mathrm{C}_{16} \mathrm{H}_{10} \mathrm{~N}_{2} \mathrm{O}_{2}\right)$ and white pigment is China clay (Tables 1 and 2 and Figures 5 and $6 a$ ). Indigo appeared as aggregates of very fine particles $(0.25-1 \mu \mathrm{m})$ of blue colour. Aggregates varied in colour from a medium blue to black depending on thickness. In natural indigo, yellow and red particles could be seen under reflected light, and some yellow and yellow-brown particles were visible through transmitted light. Many

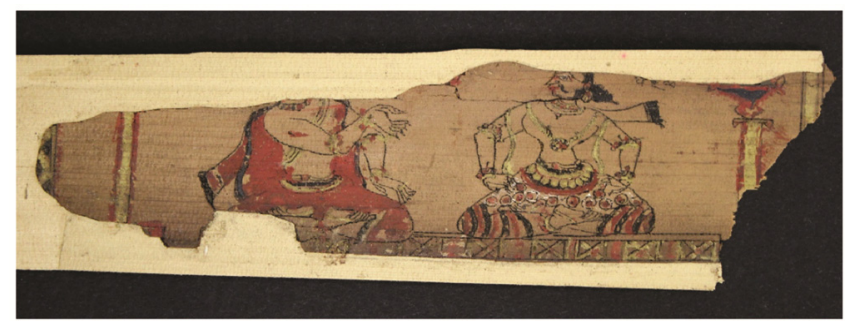

Figure 1. General view of the illustrated palm leaf manuscript collected from Odisha, India. 

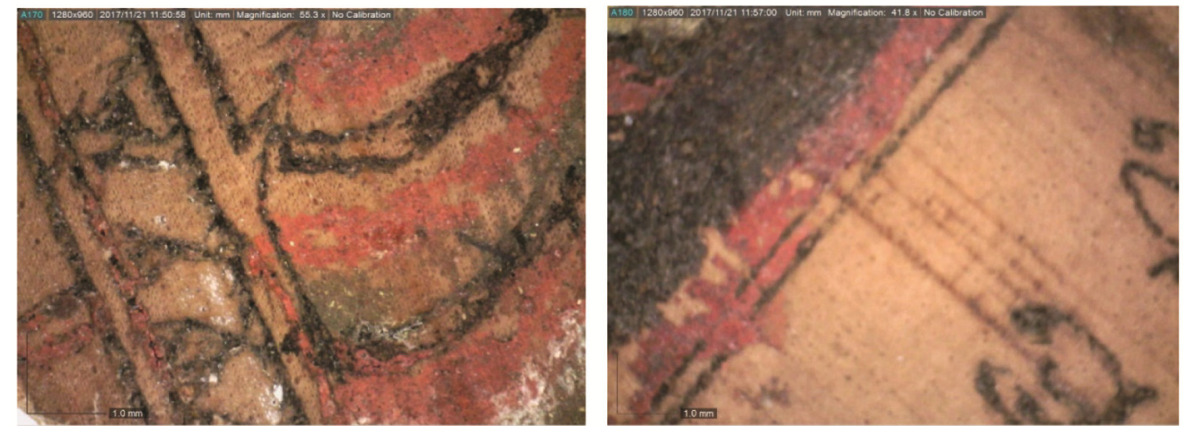

Figure 2. Microscopic view of red, green and black pigments on palm leaf.
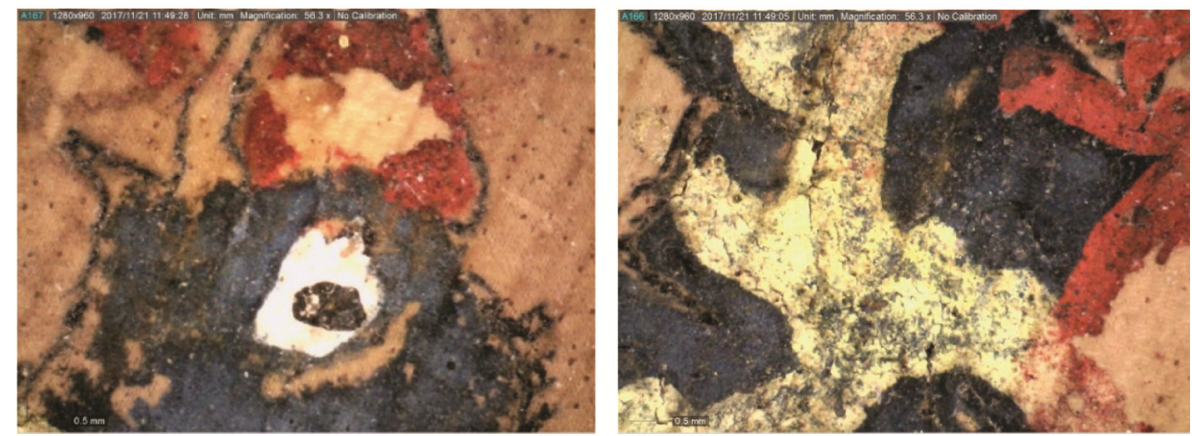

Figure 3. Microscopic view of blue, yellow and white pigments on palm leaf.

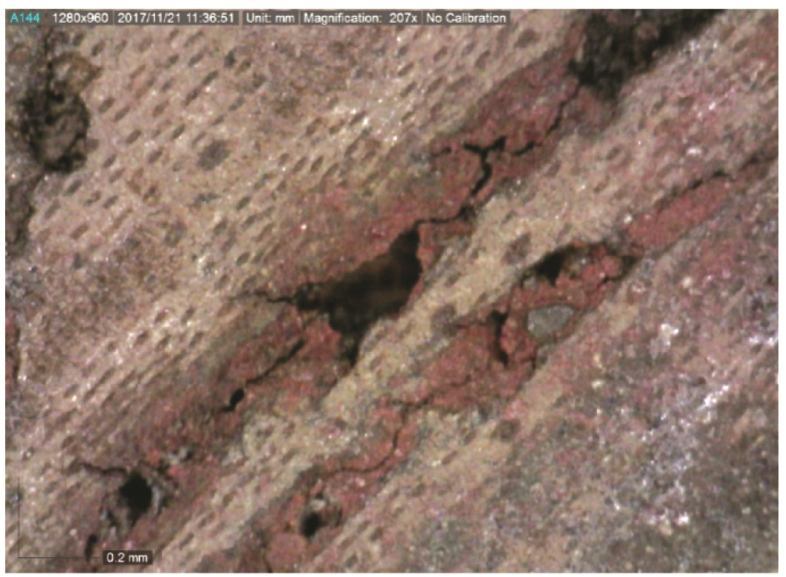

Figure 4. Representation of cell structure and tear in the manuscript.

different plants yield indigo, but its chief source is the shrub Indigofera tincotoria ${ }^{14}$.

From a scientific analysis of elemental composition of yellow pigment and its appearance under the stereomicroscope, it may be concluded that the yellow pigment is arsenic trisulphide $\left(\mathrm{As}_{2} \mathrm{~S}_{3}\right)$ (Tables 1 and 2 and Figure $6 \mathrm{~b}$ ). In the 18th century, the name 'King's yellow' was used to refer to the synthetic varieties. In the literature, the word 'orpiment' seems to have been used for both natural and artificial forms of yellow colour ${ }^{14}$. Under the microscope, orpiment appears as yellow broken frag- ments which often show cleavage planes and usually have a micaceous or plate-like structure. The particles are often elongated and clearly pleochroic, i.e. absorbing different wavelengths of light differently depending on the direction of incidence of the rays or their plane of polarization often resulting in the appearance of different colours according to the direction of view. A wide variation of size can occur, but typically particles are in the 4$20 \mu \mathrm{m}$ range. Natural deposits of mineral orpiment often associated with realgar, an arsenic sulphide mineralalso known as ruby sulphur or ruby of arsenic - are found in various places in Eastern Europe and Asia. Orpiment can be synthesized by subliming a mixture of 20 parts of sulphur and one part of arsenic oxide. A rich lemon or canary yellow with fair covering power and good chemical stability is the colourant arsenic sulphide, which naturally occurs widely but relatively in small deposits. Orpiment is known for its strikingly bright yellow colour, though it can also be bright orange or lustrous brown. The name 'orpiment' is derived from the Latin word auripigmentum, meaning gold pigment. Orpiment is a mineral often associated with bright Realgar and may form in strikingly coloured and unique mineral combinations. Orpiment contains a significant amount of poisonous arsenic and by itself is somewhat toxic in nature. It is a photosensitive mineral which will eventually get dull and develop a white powdery film upon prolonged exposure to light. Due to instability of orpiment, it is always advised to store the manuscripts enclosed and covered to 


\section{RESEARCH COMMUNICATIONS}

Table 1. Brief description of pigments used on palm leaf manuscripts and their chemical composition according to SEM-EDX analysis and stereomicroscopic observations

\begin{tabular}{ll}
\hline Pigment & \multicolumn{1}{c}{ Chemical compound } \\
\hline White & China clay, $\mathrm{AI}_{2} \mathrm{O}_{3} \cdot \mathrm{nSiO} \cdot \mathrm{nH}_{2} \mathrm{O}$ \\
Red & Cinnabar or vermillion, $\mathrm{HgS}$, iron-oxide red, $\mathrm{Fe}_{2} \mathrm{O}_{3}$ and probably some red dye \\
Yellow & Orpiment, $\mathrm{As}_{2} \mathrm{~S}_{3}$ \\
Blue & Indigo, $\mathrm{C}_{16} \mathrm{H}_{10} \mathrm{~N}_{2} \mathrm{O}_{2}$ \\
Green & No green pigment was used; green colour was achieved by mixing blue indigo and yellow orpiment \\
Black & Carbon black, C \\
\hline
\end{tabular}

Table 2. Elemental composition of all the pigments analysed using SEM-EDX

\begin{tabular}{lcccccc}
\hline & \multicolumn{5}{c}{ Pigments and elemental composition (wt \%) } \\
\cline { 2 - 7 } Elements & White & Red & Yellow & Blue & Green & Black \\
\hline C K & 9.89 & 9.42 & 16.47 & 16.05 & 20.97 & 27.25 \\
O K & 39.74 & 12.20 & 13.95 & 36.42 & 33.72 & 29.21 \\
Na K & 0.28 & - & - & - & 0.64 & 0.60 \\
Mg K & 0.54 & 0.33 & - & 0.76 & - & 0.87 \\
Al K & 18.82 & 1.63 & 2.65 & 15.11 & 7.62 & 8.80 \\
Si K & 23.90 & 4.18 & 4.85 & 25.85 & 13.97 & 15.64 \\
P K & 0.67 & - & 0.48 & 0.65 & 0.77 & 1.44 \\
S K & 0.42 & 3.81 & 23.08 & 1.08 & 6.35 & 1.68 \\
Cl K & 0.38 & 0.16 & - & 0.22 & - & 0.73 \\
K K & 1.70 & 0.94 & 0.65 & 1.21 & 2.58 & 2.80 \\
CaK & 0.66 & 0.69 & 0.69 & 0.63 & 2.08 & 1.65 \\
Ti K & 0.97 & - & - & 0.61 & 0.40 & 0.41 \\
Fe K & 2.04 & 1.08 & 1.01 & 1.41 & 1.80 & 3.25 \\
Hg L & - & 65.57 & - & - & - & 5.67 \\
As K & - & - & 36.18 & - & 9.11 & - \\
\hline
\end{tabular}

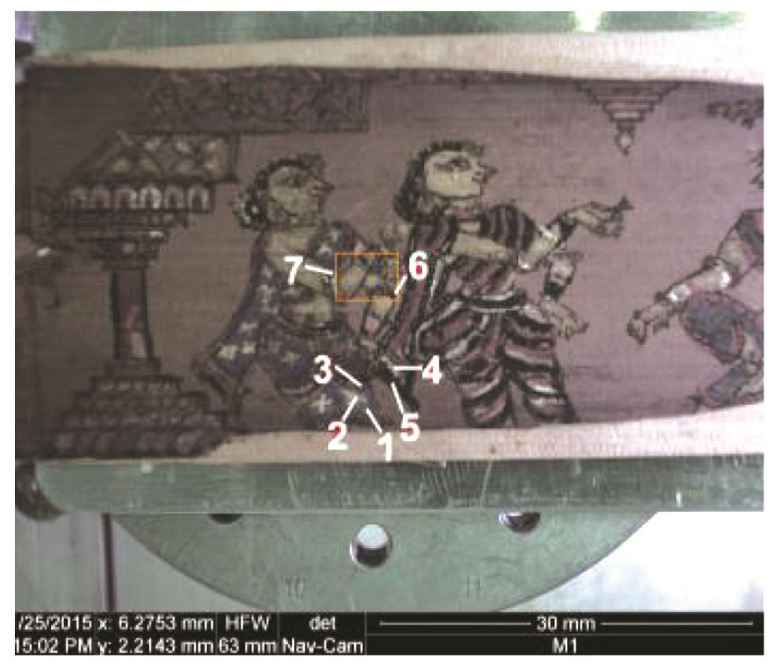

Figure 5. Photograph of illustrated palm leaf manuscript using navigation camera in the SEM chamber. (Measuring points for pigments: 1 , blue; 2 , yellow; 3 , red; 4 , white; 5 , blue.)

further prevent their constant exposure. It may not cause immediate damage, but prolonged or repeated exposure will cause deterioration ${ }^{14}$. It has been documented in the literature that yellow colour was extracted from locally available turmeric powder. Scientific studies have concluded that orpiment was used as a yellow pigment in Indian palm leaf manuscripts.

With respect to the elemental composition of red pigment, it may be concluded as mercuric sulphide ( $\mathrm{HgS}$ ) (Tables 1 and 2 and Figure $6 c$ ). It is either in the natural form as cinnabar or as an artificially prepared vermilion. In plain polarized light, vermillion appears as broken orange particles; the smallest particles tend to appear as yellow. The particles may be transparent or fibrous; some are likely to be elongated. Some particles may show pleochroism, i.e. show different colours when observed at different angles, especially with polarized light.

However, the pigments can usually be distinguished as elongated particles of vermillion show deep cleavage in their length, but the ends tend to be roughly fractured and somewhat appear to be round in shape. Vermillion a reasonably permanent pigment is brilliant red or scarlet originally made from the powdered mineral cinnabar. It is generally unaffected by normal heating and insoluble in alkalis and concentrated acids, but it is soluble in aqua regia. However, it has been found that vermillion if attempted for cleaning tends to destroy oil and varnish binders, and when an area of vermillion is cleaned it tends to be more sensitive to solvent. In some instances, vermillion shows discolouration as the red form can revert to black ${ }^{14}$. The pigment contains mercury which is toxic in nature. It is liable to darken or develop a purplish-grey surface sheen. The darkness is not a result of vermillion itself which is stable, but is caused by impurities and adulteration of the pigment. A recent study indicated that chlorine ions in the environment and impact of light may aid in decomposing vermillion into elemental mercury, which is black in finely dispersed form ${ }^{15}$. Although no chlorine was identified in the analysis, there is possibility of presence of chlorine on the surface of the sample which must have originated from an external source, most likely dirt.

According to scientific analysis of elemental composition of black paint through SEM-EDX and microscopic observations, the black pigment is carbon black (Tables 1 and 2, Figure $6 e$ ). The individual particles of lamp black are too small to be observed under light microscope. Particles tend to form aggregates in dispersions made from dry pigment eventually forming rather angular chains, 
(a)

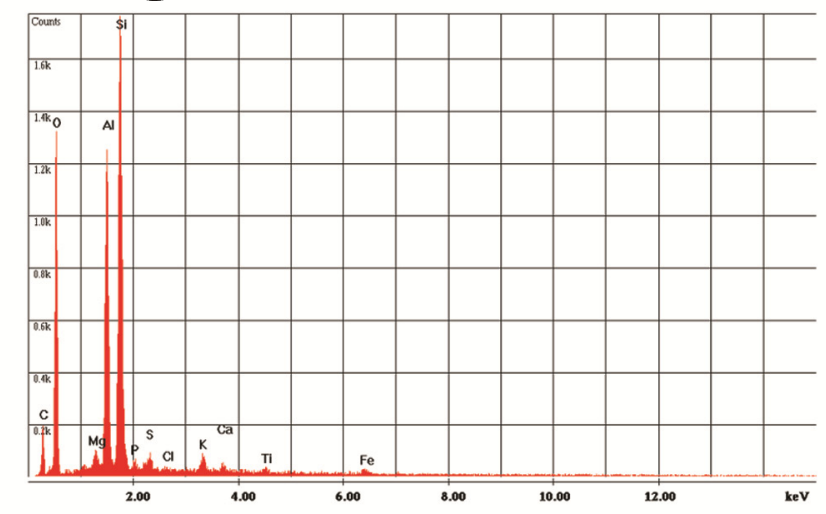

(c)

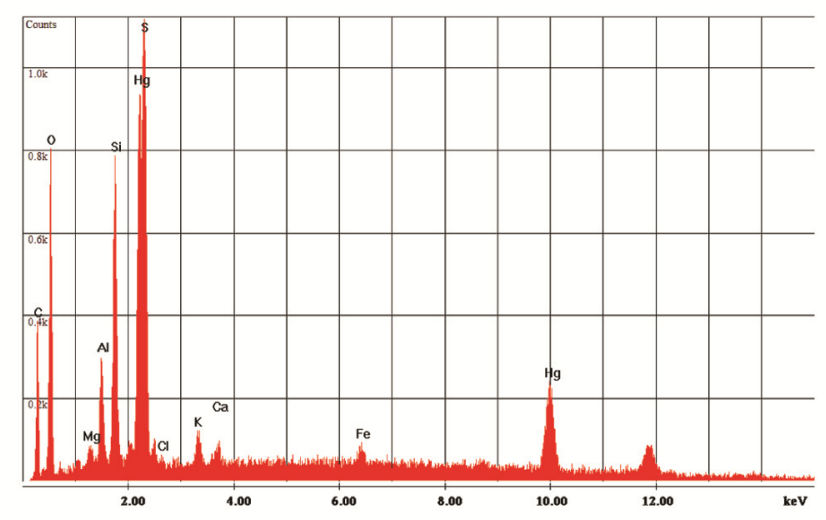

(b)

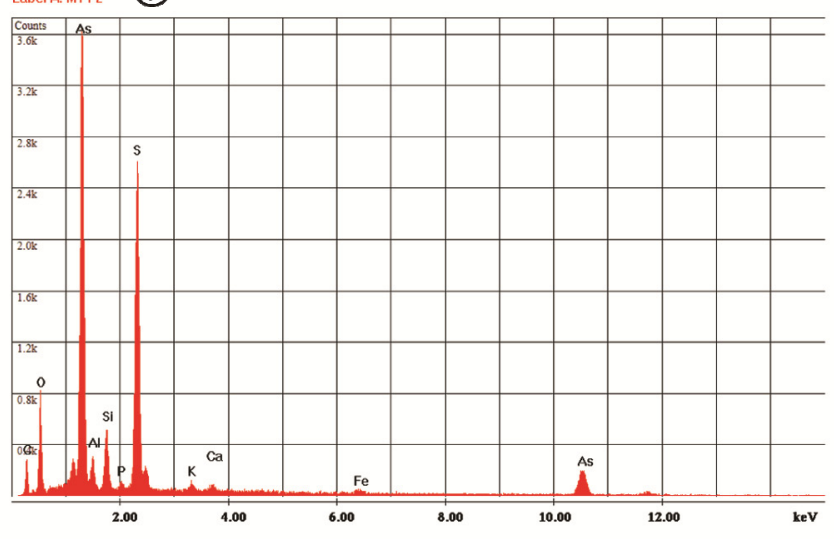

(d)

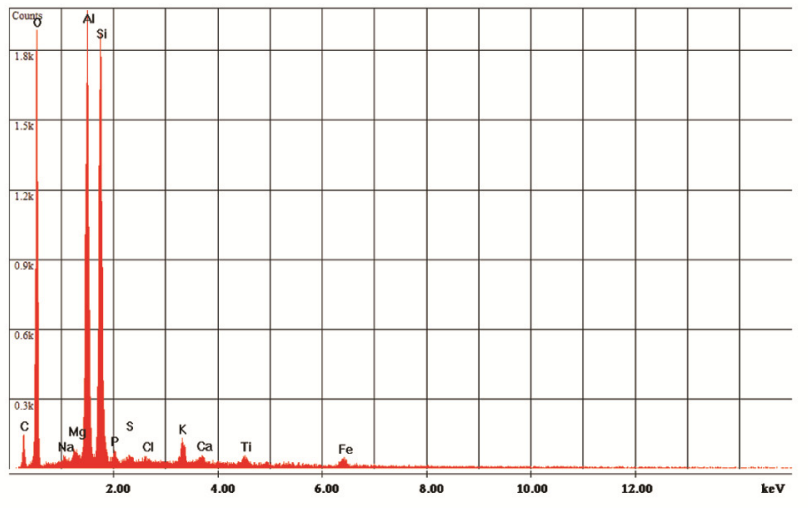

(e)

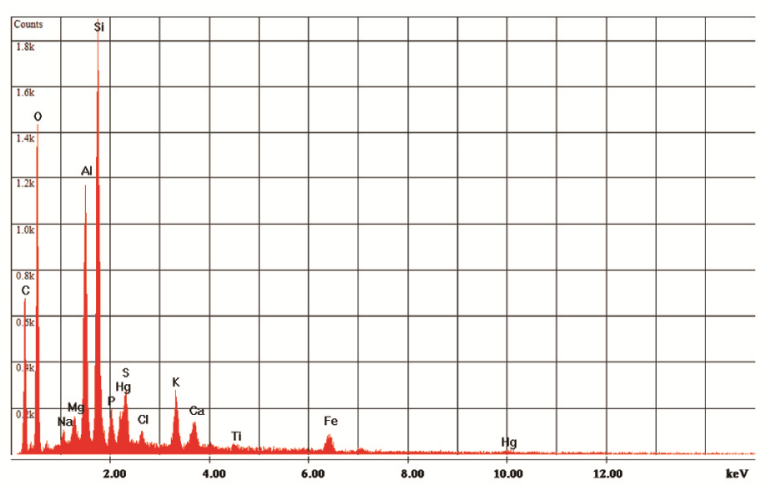

Figure 6. SEM spectra: $\boldsymbol{a}$, blue pigment; $\boldsymbol{b}$, yellow pigment; $\boldsymbol{c}$, red pigment; $\boldsymbol{d}$, white pigment; $\boldsymbol{e}$, black pigment.

and these are likely to interlock to produce an opentextured black mass. Even small aggregates are opaque and so there is no refractive index. When dispersion is made from an oil or varnish-bound paint film, it is seldom possible to break the pigment down to its component units, and the aggregates are likely to appear as solid dull black angular particles. Lamp black is smoke and in its simplest form, it is prepared by burning resinous or oil materials in a restricted supply of air, beneath a funnel on which the carbon is deposited. Lamp black is believed to be used since prehistoric times. It has a tendency to ab- sorb oil and paints. If the pigment has not been carefully prepared it does not wet out easily with water because of the residual oily material present. It has good covering power and strongly staining but tends to make mixtures in which it is incorporated heavy in tone. Hence, it has a property to smudge which leads to staining of the surface, thus making it blackish and dusty in nature ${ }^{14}$.

The green pigment was examined under the microscope and through SEM-EDX. From the results it was concluded that green pigment is a mix of the indigo (blue pigment), orpiment (yellow pigment) and China clay 
(white pigment) (Tables 1 and 2, Figures 7 and 8). In contrast, in the available literature it has been mentioned that green pigment was extracted from bean leaves. The present analysis has proved that the green pigment is a combination of three pigments, i.e. blue, yellow and white that were applied on Indian palm leaf manuscripts.

The elemental composition of the white pigment was examined under SEM-EDX. Based on the data, it was concluded that white pigment is China clay $\left(\mathrm{Al}_{2} \mathrm{O}_{3} \cdot \mathrm{nSiO}_{2} \cdot \mathrm{nH}_{2} \mathrm{O}\right)$ (Tables 1 and 2 and Figure $6 d$ ). Clay is a natural material produced by weathering of feldspathic rocks, and usually occurs as secondary deposits. It is found in all parts of world and is generally present in earth colours. Most clays contain some lime, sand or amorphous earth. The clay particles are less than $2 \mu \mathrm{m}$ and in optical quality, all the particles are likely to be small $(<3 \mu \mathrm{m})$ and have low relief as well as low birefringence. If iron or organic material is present, the particles may be coloured. Therefore, clays that contain ferric

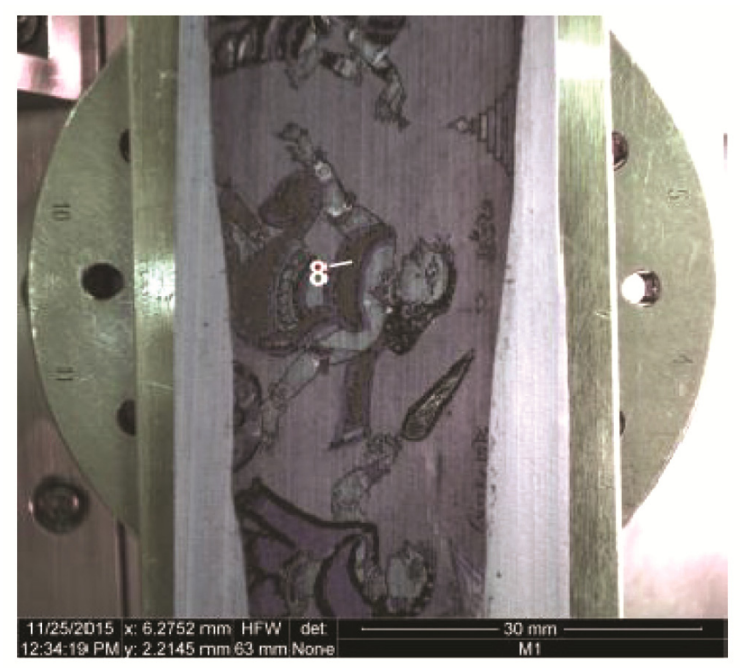

Figure 7. Photograph of illustrated palm leaf manuscript using navigation camera in the SEM chamber (measuring points for green pigment 8).

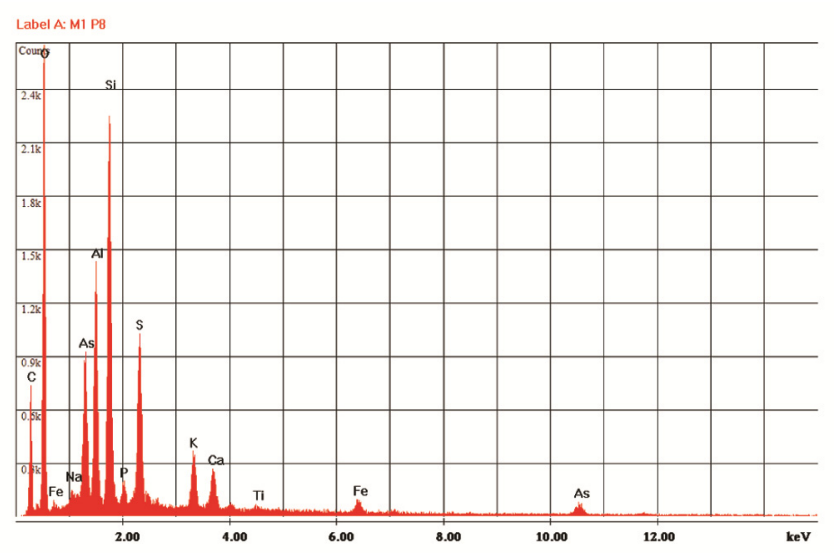

Figure 8. SEM spectra of green pigment. hydroxide are yellow; the presence of oxide results in a red or reddish material which is known as red bole or ruddle.

The ancient palm leaf manuscripts are generally found in coastal regions of Indian, mainly in Kerala, Tamil Nadu, Andhra Pradesh and Odisha. The palm leaves are subjected to many treatments to make them suitable for writings or illustrations. The writings or paintings on palm leaf are done using various colours sourced from locally available materials. The pigments used for writings/ illustrations have been well documented from other cultures, but not for ancient Indian palm leaf manuscripts. One of the prime reasons is that the owners of such ancient works of art are not willing to part with their materials. Although many non-invasive techniques have been applied in analytical studies, the scenario has not changed in the Indian context. Since different colourants have been used in different areas of India for palm leaf illustrations, we could only collect few folios sourced from Odisha for characterization of the pigments. From SEM-EDX and microscopic analysis, it is observed that some pigments like orpiment used for yellow colour are photosensitive and should not be exposed to light illumination for longer duration. It is not possible to undertake necessary preventive measures for the protection of palm leaf manuscripts without knowing their constituent materials. Scientific studies will help towards long-term preservation of these manuscripts. The mercuric sulphite used for red pigment is not only toxic, but can destroy the palm leaf binder and discolour to deep black leading to complete decomposition into elemental mercury, if necessary preventive measures are not taken for its storage and display.

The analytical studies have also now clarified many of the ancient beliefs like use of extract of bean leaves for green colour. The present study has demonstrated that green colour used in Odisha palm leaf manuscript is a mixture of blue, yellow and white pigments. Although in many ancient Indian wall paintings lapis lazuli imported from Persian countries was found applied for blue ${ }^{16}$, in the palm leaf manuscript used in this study indigo was detected for blue colour. Similarly, for yellow the pigment used is orpiment and for black colour lamp black has been exploited. Therefore, all precautionary measures must be taken for display, preservation and storage of these materials to avoid any damage.

From this study, it can be concluded that green pigment is a mixture of indigo, orpiment and China clay as against the earlier belief that it was extracted from bean leaves. Similarly, contrary to earlier belief that yellow pigment was sourced from turmeric powder, this study shows the use of mineral colour orpiment for yellow in Indian palm leaf manuscripts. Our results show that indigo has been used for blue, China clay for white, vermillion or cinnabar for red and lamp black for black colouration. As some of these pigments are photosensitive, the palm leaf 
manuscripts should not be exposed to light for long duration. Some of these traditional materials act as a catalyst in the process of deterioration on palm leaf manuscripts. Thus, it can be concluded that in Indian palm leaf illustrations, mostly mineral colours have been used.

1. Kesavan, B. S., The Book in India: A Compilation, National Book Trust, New Delhi, 1985

2. Dharmalingam, U. K., Black and White in Indian Typography, Association Typographique Internationale, Hongkong, Hongkong, 2012, pp. 1-11.

3. Naik, B. S., Typography of Devanagari-Volume 1, Directorate of Languages, Mumbai, 1971.

4. Freemen, R., Turning over old leaves: palm leaves used in South Asian manuscripts. The Book and Paper Group Annual, Amerian Institute of Conservation, Minneapolis, Minnesota, 2005, pp. 99102.

5. Agarwal, O. P., Conservation of Manuscripts and Paintings of South-East Asia, Butterworth, London, UK, 1984.

6. Agus, N. A., Mydin, M. O. and Ulang, N. H., Biomimcry of palm tree leaves form and pattern on building form. EDP Sciences, Web of Conferences 3, 01024, 2014, 1-6.

7. Akca, D. and Gruen, A., Re-sequencing a historical palm leaf manuscript with boundary-based shape descriptors. In International Archives of the Photogrammetry, Remote Sensing and Spatial Information Sciences, 19th CIPA International Symposium, Antalya, Turkey, 2003, vol. XXXIV, part 5/C15, pp. 55-60.

8. Das, J. P., Chitra Pothi: Illustrated Palm Leaf Manuscripts from Orissa, Niyogi Books, New Delhi, 2007.

9. Kumar, D. U., Sreekumar, G. V. and Athvankar, U. A., Traditional writing system in southern India - palm leaf manuscripts. Design Thoughts, 2009, pp. 2-7.

10. Patnaik, D. P., Palm-Leaf Etchigs of Orissa, Abhinav Publications, New Delhi, 1989.

11. Sahoo, J., A selective review of scholarly communications on palm leaf manuscripts. Libr. Philos. Pract. (e-journal), 2016, 1397.

12. Dyke, Y. V., Sacred leaves: the conservation and exhibition of early Buddhist manuscripts on palm leaves. The Book and Paper Group Annual, American Institute of Conservation, Washington DC, USA, 2009, vol. 28, pp. 83-97.

13. Guy, J., Palm Leaf and Paper: Illustrated Manuscripts of India and South-east Asia, National Gallery of Victoria, Melbourne, Australia, 1982.

14. Mactaggart, P. and Mactagggart, A., A Pigment Microscopist's Notebook, Mactaggart, Chard, UK, 1985.

15. Spring, M. and Grout, R., The blackening of vermillion: analytical study of the process in paintings. Natl. Gallery Tech. Bull., 2004, 23, 50-61

16. Frison, G. and Brun, G., Lapis lazuli, lazurite, ultramarine 'blue', and the colour term 'azure' up to the 13th century. J. Int. Colour Assoc., 2016, 16, 41-55.

ACKNOWLEDGEMENTS. We thank Dr B. R. Mani (National Museum Institute, New Delhi) for support. We also thank Dr Tanja Bayerova, Institute of Conservation, University of Applied Arts Vienna for constant guidance in drafting the scientific analysis for my research work during my fellowship period (Ernst-Mach Scholarship) at Vienna. We are also grateful to Prof. Rudolf Erlach, Institute of Art and Technology, Department of Archaeometry, University of Applied Arts Vienna for support while carrying out the SEM-EDX; Dr Satish Pandey and Dr Aditya Kanth (National Museum Institute, New Delhi) for invaluable inputs and support.

Received 4 December 2017; revised accepted 12 October 2019

doi: $10.18520 / \mathrm{cs} / \mathrm{v} 118 / \mathrm{i} 2 / 285-292$

\section{Mtb-HID: a unified database of host-pathogen interaction for various Mycobacterium tuberculosis strains}

\author{
Kumud Pant*, Devvret, Neema Tufchi, \\ Ajay Pandaya and Ashish Thapliyal
}

Department of Biotechnology, Graphic Era Deemed to be University, Dehradun 248 002, India

Databases developed till now for studying humanMycobacterium tuberculosis (MTB) host-pathogen interactions are scarce and pertain to specific strains of pathogen. Therefore, in the present study, a database (Mtb-HID) has been developed to serve as a unified host-pathogen interaction platform with information on interaction between various strains of MTB and humans. Mtb-HID is different from other databases since it houses information about multiple strains and is an extensive integrated repository of experimental host-pathogen protein-protein interaction (HP-PPIs) data imported from various public databases and derived from interolog-based HP-PPIs. Currently, Mtb-HID hosts records of interaction between five MTB strains and human host. It is freely accessible at http://www.pantlab.co.in/mtb-hid/.

Keywords: Database, host-pathogen interaction, humans, Mycobacterium tuberculosis.

MYCOBACTERIUM TUBERCULOSIS (MTB) is the causative agent of tuberculosis (TB), one of the most devastating diseases. Around 10 million people are infected with TB worldwide, of which 2.7 million cases belong to India alone $^{1}$. Though extensive efforts have been made by the World Health Organization (WHO), it is difficult to predict whether the disease will be eradicated by 2050 or not. The literature suggests that various strains of MTB show different patterns of infection in the host ${ }^{2}$. Virulence and pathogenesis of MTB lead to disease development in the host. Several mechanisms of action from the pathogen as well as host are involved in establishing the disease. Molecular interactions between host cells and specific microbial products play an important role in gaining pathogenesis. As a result, various changes occur in the host cell functioning, thus promoting the pathogen to invade the host cell and tissue ${ }^{3}$.

MTB is a member of the Mycobacteriaceae family. It is a Gram-positive, acidfast bacterium ${ }^{4}$. It is considered to be acid fast because of its cell wall which is made up of lipids. It resists the Gram stain and thus acid is used for staining process 5 . The genome of MTB comprises approximately 4.4 million base pairs, containing around 4000 genes with high GC content ${ }^{6}$. Though the genome is highly conserved due to the co-evolutionary process,

*For correspondence. (e-mail: pant.kumud@gmail.com) 